\title{
Repeatability of family means in early generations of potato under heat stress
}

\author{
César Augusto Ticona Benavente ${ }^{1 *}$, César Augusto Brasil Pereira Pinto ${ }^{1}$, Izabel Cristina Rodrigues de Figueiredo ${ }^{1}$ and Guilherme \\ Henrique Martins Rodrigues Ribeiro ${ }^{1}$
}

Received 10 September 2010

Accepted 17 October 2011

\begin{abstract}
The selection of potato clones for yield is usually effective from the second clonal generation. It would however be ideal to select from the seedling generation $(S G)$ or the first clonal generation $(F C G)$. The aim of this study was to evaluate the repeatability of selection at the family level performed in the early generations with the subsequent generations, for tuber yield and specific gravity in the warm season. Thirty families were evaluated in the SG, FCG and the second, third and fourth clonal generation, without any selection. In this way, adjusted means of the 30 families were obtained for each generation. Selections were simulated independently in the different family generations, and then the repeatability of these families among generations verified, using the same selection intensity. The results showed that the family selection in the SG and FCG for specific gravity and in the FCG for tuber yield is efficient, at mild as well as warm temperatures.
\end{abstract}

Key words: Solanum tuberosum, early selection, family selection, selection intensity.

\section{INTRODUCTION}

The breeding strategy in potato is usually based on clonal selection (Ross 1986, Mackay 1987). Parents of interest are crossed to obtain as many plants as possible. Clones are selected and evaluated visually or based on statistical designs from the second clonal generation (SCG). The traits that could be selected before the SCG would be traits with high heritability such as color and skin texture, tuber shape and eye depth (Schaalje et al. 1987). With a view to a significant reduction of the size of the population to be tested in the field, thus reducing the costs of the improvement process, family selection was recommended (Simmonds 1996). This has been used for perennial plants and vegetative reproduction, as for example for acerola (Paiva et al. 2002), sugar cane (Skinner et al. 1987, Jackson et al. 1995) and potato (Bradshaw et al. 2000, Gopal 2001, Bradshaw et al. 2009). Studies on family selection from the seedling generation ( $\mathrm{SG}$ ) in potato showed the efficiency of this methodology for several quantitative traits such as yield, mean weight and number of tubers, etc. (Brown et al. 1987a, Neele and Louwes 1989, Gopal 1997, Bradshaw et al. 1998).

In Brazil, specifically in the South, and in the Triângulo Mineiro in the state of Minas Gerais, potatoes are planted three times a year: in the dry season (January to March), winter (April-July) and rainy season (August-December). Although producers choose higher fields to plant their crops in the dry and rainy seasons, periods with higher temperatures than appropriate for the crop are common. Temperatures above $25^{\circ} \mathrm{C}$ reduce yields, increase disease incidence, reduce the tuber dry matter content and raise

\footnotetext{
${ }^{1}$ Universidade Federal de Lavras (UFLA), Departamento de Biologia, C.P. 37, 37.200-000, Lavras, MG, Brazil. *E-mail: cesar.benavente@gmail.com
} 
the incidence of physiological disorders (Levi and Veilleux 2007)

Today the effect of heat on plant physiology is a subject that arouses enormous interest, in view of the proven fact of global climate change and its adverse effects on food production and quality (Magrin et al. 2007, Damatta et al. 2009). Hijmans (2003) estimated that by 2050 , heat would have reduced potato production in Brazil by $23 \%$. In a review on the adverse effect of heat on different stages of the potato crop and the strategies that could be used to evaluate heat tolerance at the individual clone level, Levi and Veilleux (2007) mentioned that one such strategy would be to breed tolerant cultivars.

The purpose of this study was to evaluate the repeatability of families selected in earlier generations with that of later generations, in the warm season, for the traits tuber yield and specific gravity.

\section{MATERIAL AND METHODS}

Advanced clones of the potato breeding program of the Federal University of Lavras (UFLA) were intercrossed or crossed with cultivars to obtain the progenies of this study. Each progeny had known sources of heat tolerance, which were selected from studies by Menezes et al. (2001) and Lambert and Pinto (2002) (Table 1).

The pedigree of the clones CBM, ESL, GSI and SR1, parents of the clones in this study, includes the clones LT7, LT-9 and DTO-28, which were released as heat-tolerant by the International Potato Center (CIP, Peru). In other words, one or more heat-tolerant clones were part of the ancestry of every family in this study.

The experiments were performed in the experimental area of the Biology Department of UFLA. Thirty families were evaluated, each represented by on average 85 clones in the seedling generation (SG) and grown in pots in a greenhouse. A total of 40, 30, 24 and 20 plants per family were used in the first (FCG), second (SCG), third (TCG) and fourth (QCG) clonal generation, respectively.

The harvest of the SG was at the individual plant level and only one tuber per clone was selected. Only tuber specific gravity was evaluated in this generation, calculated by the method of weight in air and weight in water, obtained by hydrostatic weighing for each family. The other generations were planted in a randomized complete block design with four replications. The plant spacing was $0.5 \times 0.8 \mathrm{~m}$.

Harvesting and evaluations of tuber yield (TY) and specific gravity (TSG) were performed at the level of individual plants within each plot. Also, from the SG to SCG, 80 clones from four families were evaluated in the same experiments to verify correlations at the individual plant level.

The adjusted means were calculated by the method of least squares for each family in each generation. The repeatability of the families was assessed by two methods. The first was based on Pearson's correlations of the adjusted family means of all generations. In the second different family selection intensities were simulated, using the software R (R Development Core Team 2008). For this purpose, the 30 families in each generation were classified and family selection simulated, applying the same selection intensities independently to all generations. The repeatability was calculated as the percentage of coincident families when the same selection intensity was applied to two generations. Only combinations which included the SG or FCG were considered.

\section{RESULTSAND DISCUSSION}

High temperatures during tuberization were observed in the dry and rainy season (Table 2). In these seasons the frequency of temperatures above $20^{\circ} \mathrm{C}$ was between 45.9 and $58.3 \%$. The highest temperatures were recorded in the rainy season in the FCG, with a frequency of $31.2 \%$ of temperatures above $25{ }^{\circ} \mathrm{C}$. The most favorable growing conditions for potato were observed in the winter season of TCG, when the frequency of temperatures between 10 $20{ }^{\circ} \mathrm{C}$ was $70 \%$ (Table 2).

The correlations between generations for the trait tuber yield (Table 3 ) were significant $(\mathrm{P}<0.05$ or $\mathrm{P}<0.01$ ), low to moderate. At the level of individual clones, the correlations were low and non-significant, except for FCG $\mathrm{x}$ SCG. This result indicates that selection for tuber yield of individual clones would be advisable in the early generations (SG and FCG), as also demonstrated by Martin (1984), Swiezynski (1984), Caligari et al. (1986) and Brown et al. (1987b).

In general, the correlations between generations were lower than reported by Kumar and Gopal (2006). Most likely, the lower correlations observed in this study were due to higher temperatures, indicating the greater difficulty in obtaining gains by early selection for tuber yield at warm temperatures. Correlation estimates between the FCG with SCG and QCGwere moderate but showed that familyselection would be possible with some success in FCG for both traits. The correlations of the TCG with the 


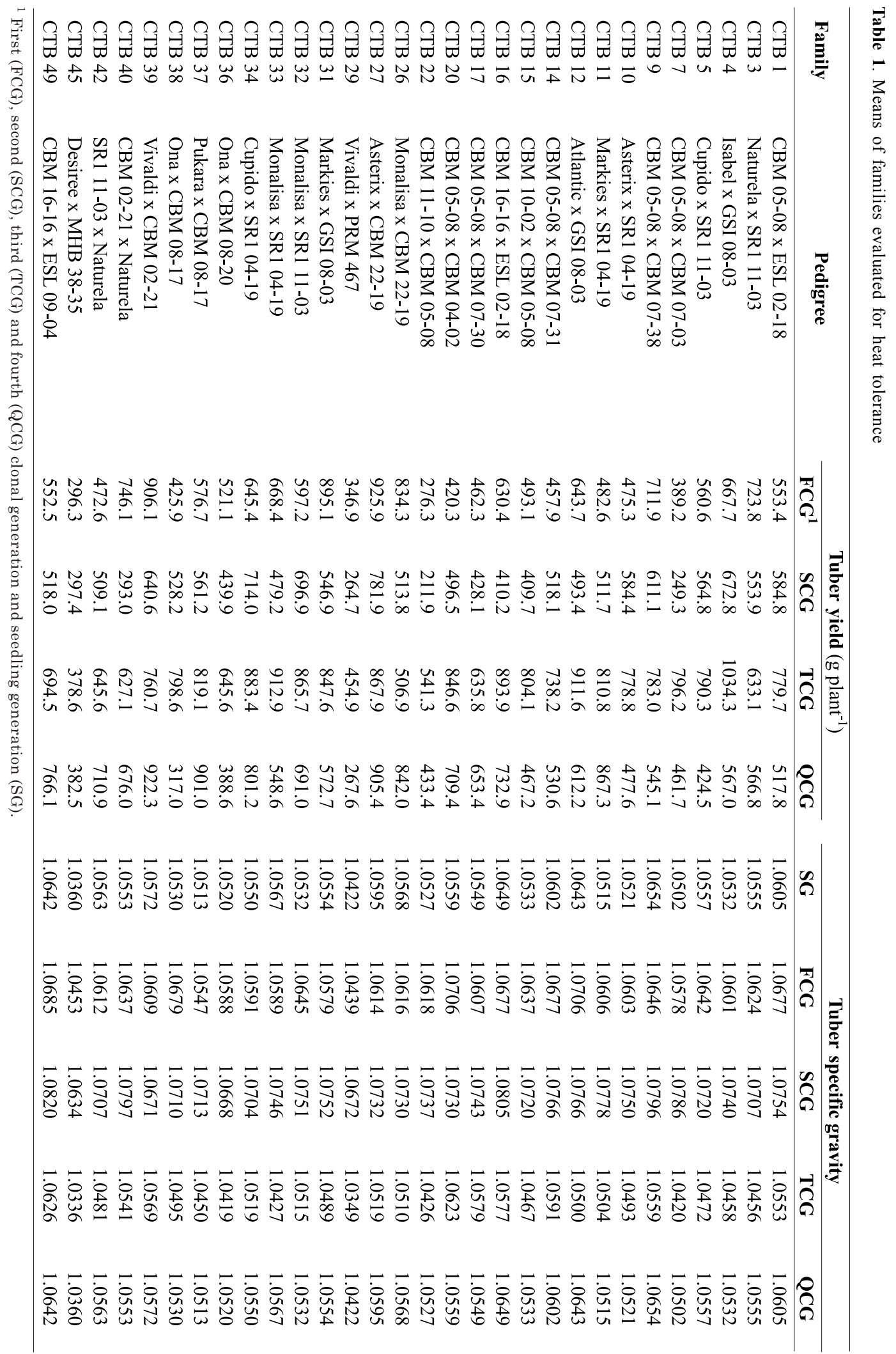


Table 2. Temperature distribution in percentage during tuberization (40 - 100 days after planting) during the experiments

\begin{tabular}{|c|c|c|c|c|c|c|c|c|}
\hline \multirow{2}{*}{ Generation } & \multirow{2}{*}{ Growing season } & \multirow{2}{*}{ Season } & \multicolumn{6}{|c|}{ Temperature $\left({ }^{\circ} \mathrm{C}\right)$} \\
\hline & & & $<\mathbf{1 0}$ & $10-15$ & $15-20$ & $20-25$ & $25-30$ & $>\mathbf{3 0}$ \\
\hline $\mathrm{SG}^{1}$ & Apr-Aug 2007 & $\mathrm{GH}^{2}$ & - & - & - & - & - & - \\
\hline FCG & Dec 2007-Apr 2008 & Dry & 0.0 & 2.1 & 50.0 & 26.0 & 20.8 & 1.1 \\
\hline SCG & Sep 2008-Jan 2009 & Rainy & 0.0 & 8.3 & 45.8 & 28.1 & 13.5 & 4.3 \\
\hline TCG & Apr-Aug 2009 & Winter & 8.9 & 36.5 & 33.3 & 17.7 & 3.1 & 0.5 \\
\hline QCG & Nov 2009-Mar 2010 & Rainy & 0.0 & 0.0 & 41.7 & 27.1 & 24.0 & 7.2 \\
\hline
\end{tabular}

${ }^{1}$ First (FCG), second (SCG), third (TCG) and fourth (QCG) clonal generation and seedling generation (SG).

${ }^{2}$ Greenhouse (GH).

Source: Instituto de Pesquisas Espaciais (2010).

Table 3. Pearson's correlations between generations for tuber yield and specific gravity

\begin{tabular}{|c|c|c|c|c|c|c|c|c|c|}
\hline & \multicolumn{5}{|c|}{ Tuber yield } & \multicolumn{4}{|c|}{ Tuber specific gravity } \\
\hline & $\mathrm{SG}^{1}$ & FCG & SCG & TCG & QCG & FCG & SCG & TCG & QCG \\
\hline SG & & & & & & $0.59 * *$ & $0.60 * *$ & $0.48^{* *}$ & $0.45^{*}$ \\
\hline FCG & $-0.09^{2}$ & & $0.60 * *$ & $0.37 *$ & $0.57 * *$ & & $0.82 * *$ & $0.66^{* *}$ & $0.77^{* *}$ \\
\hline SCG & -0.002 & $0.34 * *$ & & $0.60 * *$ & $0.49 * *$ & 0.21 & & $0.59 * *$ & $0.78^{* *}$ \\
\hline TCG & & & & & 0.29 & & & & $0.57^{* *}$ \\
\hline
\end{tabular}

* $(\mathrm{P}<0.05) ; * *(\mathrm{P}<0.01)$ by the Student's t test.

${ }^{1}$ See Table 1.

${ }^{2}$ Above the diagonal, correlation at the family level and below, at the plant level.

other generations were, in general, lower. The TCG was cultivated in the winter season, unlike the other generations that were grown at higher temperatures (Table 2). This was corroborated by the significant families $\mathrm{x}$ generation interaction (Table 4).
Unlike the observations for tuber yield, the correlations between TCG and the other generations were very similar. These results were consistent with the analysis of variance that showed no significant family generation interaction for specific gravity (Table 4).

Table 4. Combined analysis of variance of the locations for yield and tuber specific gravity

\begin{tabular}{lrcc}
\hline \multirow{2}{*}{ Sources of variation } & \multirow{2}{*}{$\mathbf{d f}$} & & MS \\
\cline { 3 - 4 } & & Tuber yield $\left(\mathrm{g} \mathrm{plant}^{-1}\right)$ & Tuber specific gravity $^{-}$ \\
\hline Generation & 3 & $1177686.20^{* *}$ & $0.01553^{* *}$ \\
Block(Generation) & 12 & $118009.53^{* *}$ & 0.00030 \\
Families & 29 & $238760.19^{* *}$ & $0.00062^{* *}$ \\
Generation x Family & 87 & $53882.78^{*}$ & 0.00264 \\
Error & 345 & 41731.68 & 0.00028 \\
\hline Mean & & 618.03 & 1.0593 \\
\hline CV & & 33.05 & 1.6069 \\
\hline
\end{tabular}

$*(\mathrm{P}<0.05)$ and ** $(\mathrm{P}<0.01)$ by the $\mathrm{F}$ test.

In the case of TSG, all correlations were significant and higher than the correlations for TY (Table 3). This indicates that the family selection for tuber specific gravity in early generations (SG and FCG) would provide higher gains than selection for tuber yield. Similarly to yield, the correlationsfortuber specific gravity at the individual clonelevel were also low and not significant. This demonstrates that clone selection for this trait in not indicated either in the early generations (SG and FCG). In general, the correlations of specific gravity between FCG and the other generations were higher than between SG and the other generations (Table 3). This demonstrates that the gain with selection for tuber specific gravity would be higher in selection ofin FCG. 
The results of the simulation to evaluate the selection intensity and repeatability of families for yield are shown in Figure 1. To understand the simulation results one must remember that the family selection can be, depending on the classification in a previous generation, favorable, unfavorable or neutral. When favorable, repeatability is greater than the value of the magnitude of selection intensity used. If unfavorable, repeatability will be lower and when neutral it will be equal to the magnitude of selection intensity. For example, if for 30 families we select $20 \%$ of superior families from two generations (six families from SG and six from FCG) and obtain a $20 \%$ repeatability (about one family), the conclusion can be drawn that the selection had a neutral effect; this selection is equivalent to a random family selection, which is calculated by: $100\left[\Sigma_{1}^{6}(1 / 30)\right]=100(1 / 5)=20$. Therefore, repeatabilities above $20 \%$ mean a positive effect of family selection, and below $20 \%$ indicate the inefficiency of family selection. One should also bear in mind that the lowest magnitudes of selection intensity indicate highest selection intensities and vice versa.

Figure 1A shows the repeatability of families for tuber yield in the dry season (FCG) with the others. It was observed that magnitudes of selection intensity $>25 \%$ can be used in the FCG for this trait, when selection is performed in the warm season (FCG) with response under similar conditions (in SCG and QCG). However, family selection in the warm season with response in the winter (TCG) was successful at greater magnitudes of selection intensity $(>30 \%)$. Therefore, the repeatability at selection intensities $>30 \%$ was similar in summer and winter. This would indicate that family selection for yield targeting heat tolerance could be performed in the warm season and in FCG with positive response to any environment, provided that the selection intensity is $>30 \%$. This idea is consistent with the studies of Brown et al. (1987b) on potato and on sugarcane by Jackson et al. (1995). One way to exploit family selection for yield would be to assess a higher number of families in a greenhouse, or in FCG, at warm temperatures, using a high selection intensity (Hogarth et al. 1997).

In the case of simulation of family selection for tuber specific gravity, repeatabilities in function of SG (Figure 1B) and FCG can be observed (Figure 1C). As in the case of tuber yield, the family selection for specific gravity with lower magnitudes of selection intensities $(<10 \%)$ could only be used when selection is conducted in the warm season (FCG, SCG and QCG).In a greenhouse, SG could be exploited for family selection for specific gravity with intensities $>20 \%$ in all clonal generations. However, the response of clones of generations selected in the warm season (FCG, SCG and QCG) was slightly higher (Figure 1B)

When family selection was performed for specific gravity in FCG, repeatability was higher in SG at intensities between 10 and $30 \%$, indicating greater efficiency of family selection in the FCG (Figure 1C).

Figure 1D shows the results of simulations of selection intensity to assess the repeatability of the selected families at mild temperatures (TCG) and their response at warm temperatures (QCG) for tuber yield and tuber specific gravity (Figure 1E). The repeatability of family selection for yield was close to the magnitude of selection intensities (Figure 1D), indicating that selection would be of no avail. For tuber specific gravity however higher repeatability than for yield can be observed when using stronger selection intensities (Figure 1E). These results support the idea that family selection for specific gravity at mild temperatures could result in a gain in the warm season. There are few studies focusing the family selection for SG, which may be explained by the fact that this traitis only important in subsequent clonal generations, when the quality of the selected clones is evaluated (Capezio et al. 1993).

Although the theoretical model of Casler and Brummer (2008) proposes a weaker selection intensity among families followed by the application of an equal or higher intensity within clonal families, the results showed that the intensities to be applied depend on the trait under selection. In the case of family selection for disease resistance, Bradshaw et al. (2009) applied selection intensities between 20 and $30 \%$ to evaluate more than 120 families in a greenhouse.

Figures 2 and 3 show the adjusted mean values of families for yield and tuber specific gravity at mild (TCG) and high temperatures (QCG). The dividing lines represent overall averages in both generations, generating four quadrants. Nine families were observed with higher mean yieldin both seasons (Figure 2, quadrant I). To be able to select seven of these families in FCG, a family selection intensity of $47 \%$ would have to be applied.

Analogously to tuber specific gravity, 10 families were identified with greater means than the overall average in the rainy season (QCG) and winter (TCG) (Figure 3, quadrant I). Nine of these families could be selected in $\mathrm{SG}$ at an intensity of $57 \%$. In the FCG, six of these families would be selected with $20 \%$. This would indicate that the family selection for specific gravity could be successfully performed in SG, provided the selection intensity is weak. 

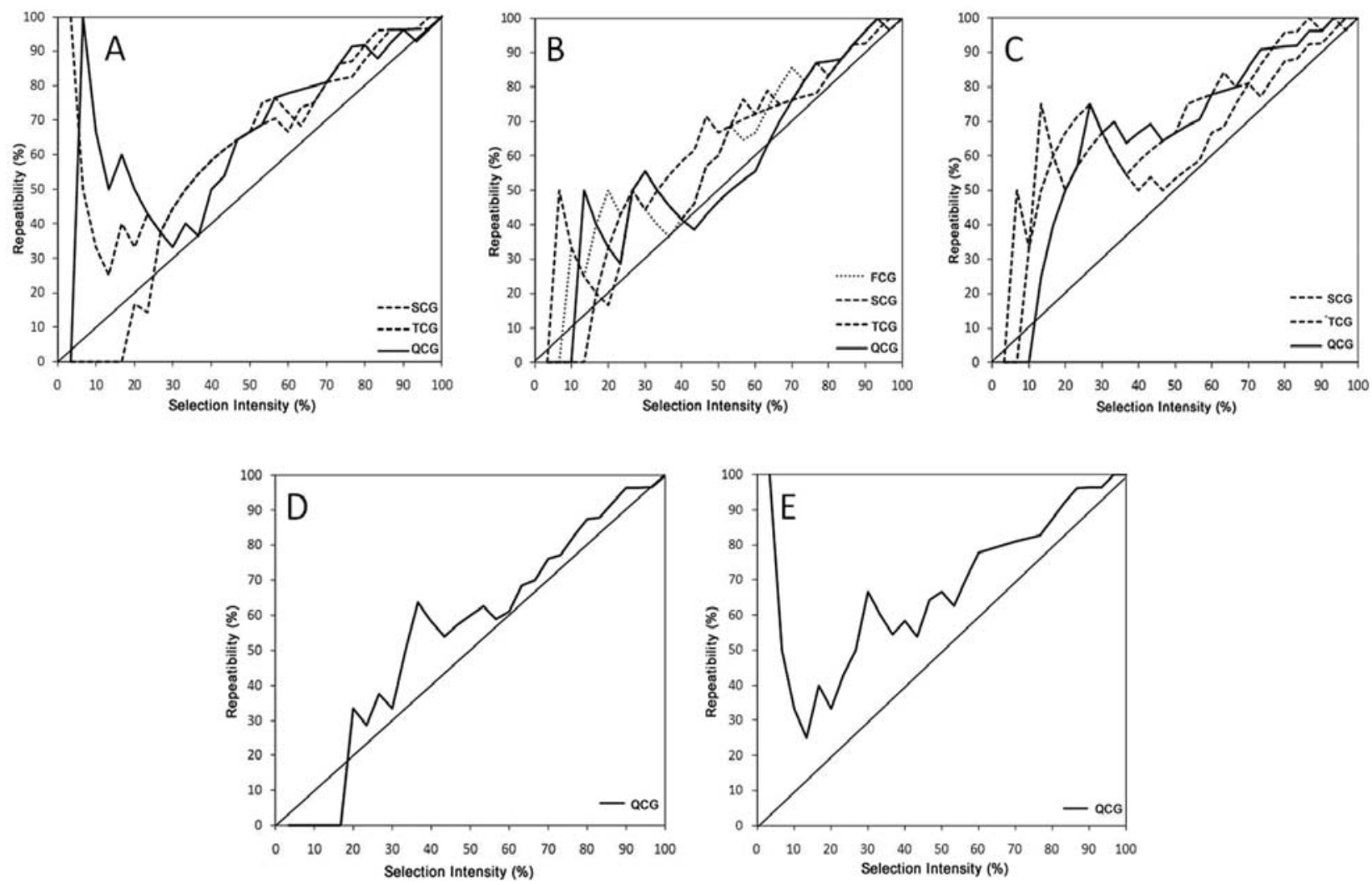

Figure 1. Simulations of the intensity of family selection and the repeatability in other generations. A) for tuber yield in FCG. B) and C) for specific gravity in SG and FCG respectively. D) for yield inTCG (winter) and E) for specific gravity inTCG (winter). The diagonal line indicates the expected repeatability if selection was neutral.

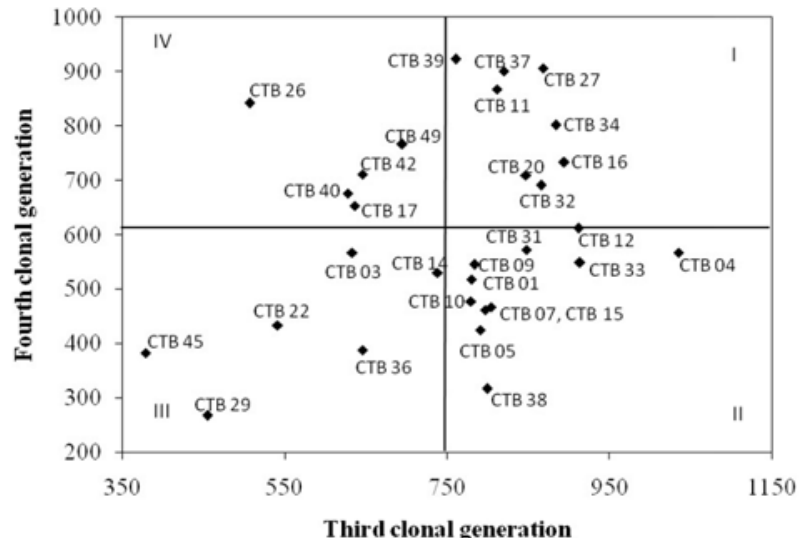

Figure 2. Family means for tuber yield $\left(\mathrm{g} \mathrm{plant}^{-1}\right)$ at warm temperatures (QCG) and in the winter (TCG). The lines represent the overall family means in both generations.

The averages of only four families were higher than the overall mean under contrasting conditions for both traits (CTB 11, CTB 12, CTB 16, and CTB 32). Therefore the exploitation of these families is likely to make the

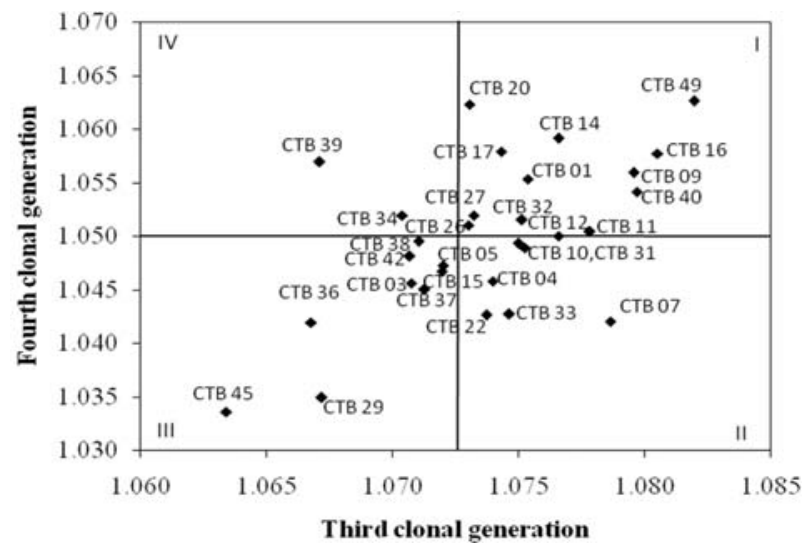

Figure 3. Family means for tuber specific gravity at warm temperatures (QCG) and in the winter (TCG). The lines represent the overall family means in both generations.

establishment of clonespossible that are adapted to mild temperatures; but even if the temperatures climbed higher, they would still be productive and achieve high specific gravity. 


\section{CONCLUSIONS}

At high temperatures, the early selection of families can be applied for tuber yield and specific gravity. Overall intensities of family selection of 20 to $60 \%$ seem indicated to obtain families with high tuber yield and mean tuber specific gravity at mild as well as warm temperatures. The selection of individual clones in the SG or FCG is not recommended for tuber yield and tuber specific gravity. Family selection for specific gravity proved more efficient than for yield and can be applied from the SG.

\section{ACKNOWLEDGEMENTS}

The first author thanks the Brazilian Federal Agency for Support and Evaluation of Graduate Education CAPES, the National Council for Scientific and Technological Development - CNPq, and the IEL - Brazil for a $\mathrm{PhD}$ scholarship.

\title{
Repetibilidade de médias de famílias em gerações precoces de batata sob condições de calor
}

\begin{abstract}
RESUMO - Geralmente a seleção de clones de batata para produtividade é eficiente a partir da segunda geração clonal. No entanto, seria ideal selecionar a partir da geração seedling (GS) ou na primeira geração clonal (PGC). O objetivo deste trabalho foi avaliar, em nivel de famílias, a repetibilidade da seleção em gerações mais precoces sobre as mais tardias, nas épocas quentes, para produtividade e peso especifico. Foram avaliadas 30 famílias na GS, PGC, segunda, terceira e quarta geração clonal, sem realizar seleção nenhuma. Logo, foram obtidas as médias ajustadas das 30 famílias para cada geração. Foram simuladas seleções de famílias nas diferentes gerações de forma independente; e depois verificada a repetibilidade dessas famílias entre as gerações utilizando igual intensidade de seleção. Os resultados mostraram que a seleção de famílias na GS e PGC para peso específico e na PGC para produtividade é eficiente, tanto em condições de temperaturas amenas como em calor.
\end{abstract}

Palavras-chave: Solanum tuberosum, seleção precoce, seleção de famílias, intensidade de seleção.

\section{REFERENCES}

Bradshaw JE, Dale MFB, Swan GEL, Todd D and Wilson RN (1998) Early-generation selection between and within pair crosses in a potato (Solanum tuberosum subsp. tuberosum) breeding programme. Theoretical and Applied Genetics 97: 1331-1339.

Bradshaw JE, Todd D and Wilson RN (2000) Use of tuber progeny tests for genetical studies as part of a potato (Sonalum tuberosum subsp. tuberosum) breeding programme. Theoretical and Applied Genetics 100: 772-78.

Bradshaw JE, Dale MFB and Mackay GR (2009) Improving the yield, processing quality and disease and pest resistance of potatoes by genotypic recurrent selection. Euphytica 170: 215-227.

Brown J, Caligari PDS and Mackay GR (1987a) The repeatability of progeny means in the early generations of a potato breeding programme. Annals of Applied Biology 110: 365-370.

Brown J, Caligari PDS, Mackay GR and Swan GEL (1987b) The efficiency of visual selection in early generations of a potato breeding programme. Annals of Applied Biology 110: 357-363.
Caligari PDS, Brown J and Abbott RJ (1986) Selection for yield and yield components in the early generations of a potato breeding programme. Theoretical and Applied Genetics 73: 218-222.

Capezio S, Huarte M and Carrozzi L (1993) Selección por peso específico en generaciones tempranas en el mejoramiento de la papa. Revista Latinoamericana de la papa 5/6: 54-63.

Casler MD and Brummer EC (2008) Theoretical Expected Genetic Gains for Among-and-Within-Family Selection Methods in Perennial Forage Crops. Crop Science 48: 890-902.

Damatta FM, Grandis A, Arenque BC and Buckeridge MS (2009) Impacts of climate changes on crop physiology and food quality. Food Research International 43: 1814-1823.

Gopal J (2001) Between and within variation and family selection in potato breeding programmes. Journal of Genetics and Breeding 36: 201-208.

Gopal J (1997) Progeny selection for agronomic characters in early generations of potato breeding programme. Theoretical and Applied Genetics 95: 307-311. 
Hijmans RJ (2003) The effect of climate change on global potato production. American Journal of Potato Research 80: 271279.

Hogarth DM, Cox MC and Bull JK (1997) Sugarcane improvement: past achievements and future prospects. In Kang MS (ed.) Crop improvement for the 21st century. Louisiana State University, Baton Rouge, p. 29-56.

Instituto Nacional de Pesquisas Espaciais. Available at $<\mathrm{http}: / /$ satelite.cptec.inpe.br/PCD/historico/consulta_pcda.jsp> Accessed on Mar. 7, 2010.

Jackson PA, Mcrae TA and Hogarth DM (1995) Selection of sugarcane families across variable environments. I. Sources of variation and an optimal selection index. Field Crops Research 43: 109-118.

Kumar R and Gopal J (2006) Repeatability of progeny mean, combining ability, heterosis and heterobeltiosis in early generations of a potato breeding programme. Potato Research 49: 131-141.

Lambert ES and Pinto CABP (2002) Agronomic performance of potato interspecific hybrids. Crop Breeding and Applied Biotechnology 2: 179-188.

Levy D and Veilleux RE (2007) Adaptation of potato to high temperatures and salinity-a review. American Journal of Potato Research 84: 487-506.

Mackay GR (1987) Selecting and breeding for better potato cultivars. In Abbott AJ and Atkin RK (eds.) Improving vegetatively propagated crops. Academic Press, London, p. 181-196.

Magrin G, Gay García C, Cruz Choque D, Giménez JC, Moreno AR, Nagy GJ, Nobre C and Villamizar A (2007) Latin America. In Parry M, Canziani OF, PalutikofJP, van der Linden PJ and Hanson CE (eds.) Climate Change 2007: Impacts, adaptation and vulnerability. Contribution of working group II to the fourth assessment report of the intergovernmental panel on climate change. Cambridge University Press, Cambridge, p. 581-615.
Martin MW (1984) Early generation selection methods for resistance and horticultural factors. American Journal of Potato Research 61: 383-384.

Menezes CB, Pinto CABP, Nurmberg PL and Lambert ES (2001) Combining ability of potato genotypes for cool and warm season in Brazil.Crop Breeding and Applied Biotechnology 1: 145-157.

Neele AEF and Louwes KM (1989) Early selection for chip quality and dry matter content in potato seedling populations in greenhouse or screenhouse. Potato Research 32: 293-300.

Paiva JR, Alves RE, Melo FIO, Cordeiro ER and Almeida AS (2002) Genetic progress of selections between and within Caribbean cherry open pollination progenies. Crop Breeding and Applied Biotechnology 2: 299-306.

R Development Core Team (2008) R: a language and environment for statistical computing. Version 2.10, Available at http://www.R-project.org. Accessed on Out. 25, 2009 .

Ross H (1986) Potato breeding - problems and perspectives. Advances in Plant Breeding-13, Paul Parey Scientific Pub, Berlin, 132p.

Schaalje GB, Lynch DR and Kozub GC (1987) Field evaluation of a modified augmented design for early stage selection involving a large number of test lines without replication. Potato Research 30: 35-45.

Simmonds NW (1996) Family selection in plant breeding. Euphytica 90: 201-208.

Skinner JC, Hogarth DM and Wu KK (1987) Selection methods, criteria and indices. In Heinz DJ (ed.) Sugarcane improvement through breeding. Elsevier, Amsterdan, p. 409-453.

Swiezynski KM (1984) Early generation selection methods used in polish potato breeding. American Journal of Potato Research 61: 385-394. 